\title{
A case of self slitting of throat as a result of cannabis induced psychosis
}

\author{
Mohd Kaleem Khan ${ }^{1 *}$, Jamal Azmat ${ }^{2}$, Faiz Ahmad ${ }^{3}$ \\ ${ }^{1-3}$ Assistant Professor, ${ }^{1,3}$ Dept. of Forensic Medicine, ${ }^{1,3}$ J.N. Medical College, ${ }^{2}$ A.K. T. College, ${ }^{1-3}$ Aligarh Muslim University Aligarh,Uttar \\ Pradesh, India
}

*Corresponding Author: Mohd Kaleem Khan

Email: mkk435@yahoo.co.in

\begin{abstract}
Self injuring or harming or mutilating behaviour is defined as a deliberate alteration in the body tissue or destruction of body tissue in the absence of conscious suicidal thought. Patients of mental disorder may deliberately cause hundred of wounds on themselves without any intention which may actually have a cumulative effect that is the death of the patient. It seems self harming behaviour has a vast spectrum, if injuries in its domain right from mild scratches to amputation of body parts to enucleation of eyes. Patient with self behaviour almost always has suffered from mental disorders like paranoid schizophrenia or syndromes of self mutilation which may have some religious overtone attached to it.

Here we present a case of a 28 -year-old male with cut throat injury in the middle of the neck in the front just above the thyroid cartilage as a result of cannabis induced psychosis.
\end{abstract}

Keywords: Self Mutilation, Throat Slit, Cannabis Induced Psychosis.

\section{Introduction}

Self-mutilation, self-injuring or self-harming behavior has been defined as deliberate destruction or alteration of body tissue in the absence of conscious suicidal intention. ${ }^{1}$ It seems incidence of self-mutilation is considerably more among women. ${ }^{2,3}$ People suffering from may cause hundred of wounds on themselves without any intention which may actually have a cumulative effect that is the death of the patient. A syndrome (Klingsor syndrome) of being self mutilation of genitals mostly in invariably in males suffering from paranoid schizophrenia and often with strong religious overtone attached to their delusion is well recognized. ${ }^{4}$ It seems self harming behaviour has a vast spectrum, if injuries in its domain right from mild scratches to amputation of body parts to enucleation of eyes. ${ }^{5} 6$ Common psychiatric associations with self-harming behavior includes psychotic and mood disorders like dementia, borderline personality disorder, substance abuse and mental retardation. Patients with some syndromes like the Cornelia De Lange, Prader-Willi and Lesch-Nyhan Syndromes are particularly prone to Self-mutilation. Aboseif et al in a study of 14 patients with self-inflicted genital injuries, found $65 \%$ of cases to be psychotic and $35 \%$ to be non psychotic. ${ }^{7}$ This report is an unusual case of a man with the self slitting of the throat as a result of cannabis induced psychosis.

\section{Case report}

A 28-year-old male was brought his brothers to emergency department of JNMCH Aligarh at 11:50 AM on $30^{\text {th }}$ April 2019 with C.No. 25125 with cut throat injury in the middle and front of the neck just above the thyroid cartilage. The injury was about $6 \mathrm{~cm}$ in length horizontally and about 1.5 $\mathrm{cm}$ in width (Figure 1). Trachea and underlying structures were safe none of neurovascular structure was involved (Figure 2). The patient was hemodynamically stable, conscious, oriented and was able to speak. The patient was attended immediately wound was examined in detail. It was a clean cut injury with no horizontal cut marks, placed horizontally in the middle and front of the neck just above the thyroid cartilage. Skin and superficial muscle (platysma) was cut with sparing all the vital structures including trachea and neurovascular bundle. The Wound closed in two layers and the patient recovered well. The patient was referred to Forensic Medicine and psychiatry units for self harming behaviours.

On detailed history evaluation it was found that the patient was chronic a smoker of cannabis leaves ("marijuana", "marihuana", "hashish" and "Ganja"), commonly known as Ganja in this region of the country. He was having frequent episodes of hallucinations and had wondering tendency. This morning he was wondering in the market place with no motive, suddenly took a shaving knife (Ustura) from a barber's shop and slit his throat without any hesitation or warning. Wound shows cutting of the skin and platysma with tailing on the left side. It's a clean cut with no hesitations, cut, mark placed almost horizontally in the center of the neck. Further details revealed that certain command, leading him to do so to get rid of all his sufferings in life. Patient use to hear such voices earlier also to end his suffering, but was unable to follow the command. The patient is unmarried and living with his two brothers in a small house in a slum area of the city.

The treatment was started with $2 \mathrm{mg}$ risperidone twice daily, the patient showed marked improvement and no symptoms of delusion and hallucination, further no fresh history of cannabis intake was reported. After one month follow up, patient though showed a history of poor compliance of drug intake but there was no reversal of symptoms. This suggests that psychosis was mainly due to cannabis intake. 


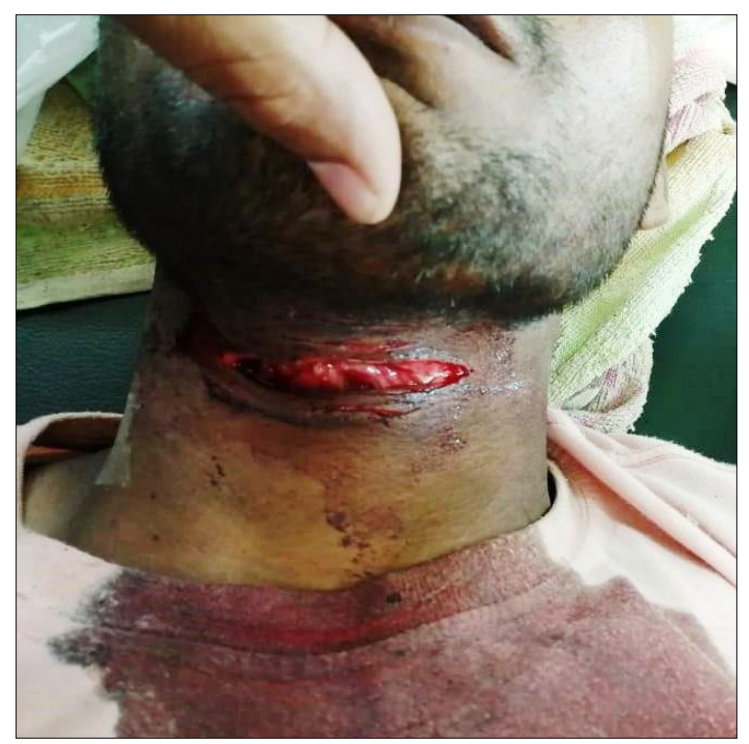

Fig. 1. Slit throat spindle shape wound

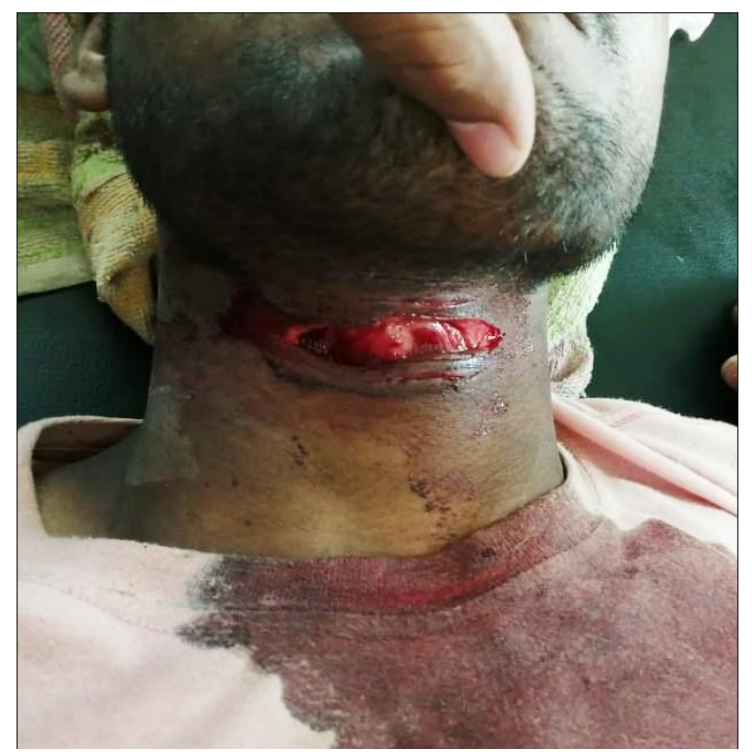

Fig. 2. Slit throat showing deeper tissue

\section{Discussion}

Cannabis, also known as "marijuana", "marihuana", "hashish" and "Ganja", is a psychoactive drug, which is forbidden in many states of USA. It is banned substance in India ${ }^{8}$ though it is quite frequently available in the forms of dried leaf for smoking. ${ }^{9}$ A new trend is developing for the smoking of marijuana in the form of locally made cigarettes than the old hookah form which had some social and religious overtone. Marijuana, hashish and other psychoactive products obtained from Cannabis sativa are the most produced illicit drugs around the world. ${ }^{10}$

The potency of cannabis products is determined by its 9-Tetrahydrocanabinnols (9- THC) content, usually given as a percentage of 9-THC. ${ }^{11}$ Cannabis contains about 421 different chemical compounds, including 61 cannabinoids. ${ }^{12}$ During the consumption by smoking, more than 2000 compounds can be produced by pyrolysis. Eighteen different classes of chemicals, including nitrogen compounds, amino acids, hydrocarbons, sugars and fatty acids can contribute to the single known pharmacological and toxicological properties of cannabinoids. ${ }^{13} \mathrm{New}$ found role of cannabinoids in the treatment of nausea and pain management in patients receiving chemotherapy has prompted many states of the USA to legalize its production in the name of medical Marijuana. ${ }^{14}$ In India some states like Uttra Khand have allowed production of Marijuana only for medicinal purpose. ${ }^{15}$ Dopamine seems to be closely related to self mutilation as a strong dose of dopaminergics (amphetamine) can enhance self mutilation. Observations have been made that some substances like cocaine and cannabis can interact with dopamine with dopamine transporters to alter synaptic transmission. ${ }^{16}$ It seems 9-THC is involved in animal psychosis by enhancing dopaminergic neurotransmission. Increased genetic vulnerability in humans increases the risk of psychosis and neurological impairment cannabis consumed subjects. ${ }^{17}$ loss of inhibitory control of the brain can lead to mutilation behavior in addicted subjects. ${ }^{18}$

Cannabis and its related products are banned in NDPS act $1985 .{ }^{8}$ Despite heavy penalties and punishment still cannabis consumption has increased. Cannabis and its products are preferred in different ceremonies which is still a driving force for its consumption. We need a strict implementation of prohibitory laws and spread awareness to keep people away from cannabis and its products.

\section{Source of Funding: None.}

Conflict of Interest: None.

\section{References}

1. Coons PM. Self amputation of the breasts by a male with schizo-typal personality disorder. Hosp Community Psychiatry 1992;43:175-6.

2. Greilsheimer H, Groves JE. Male genital self-mutilation. Arch Gen Psychiatry 1979;36:441-6.

3. French AP and Nelson HL. Genital self-mutilation in women. Arch Gen Psychiatry 1972;27:618-20

4. Harrech Y. El. Genital self-amputation or the Klingsor syndrome; Successful non-microsurgical penile replantation; Urol Ann 2013;5(4):305-8.

5. Castro HM. A Case of Attempted Bilateral Self Enucleation in a Patient with Bipolar Disorder, Ment Illn. 2017;22;9(1):7141

6. Khan MK, Usmani MA, Hanif SA. A case of self amputation of penis by cannabis induced psychosis; J Forensic Leg Med. 2012;19(6):355-7.

7. Aboseif S, Gomez R, Mc Aninch JW. Genital self mutilation. $J$ Urol.1993; 150:1143-6

8. Narcotics Drugs and Psychotropic Substances Act (NDPS) 1985

9. Ghodse Hamid A. Cannabis psychosis addiction 1986;81(4): 473-8

10. CND (2006), the World drug situation with regard to drug trafficking: Report of the Secretariat,Comissão das Nações Unidas sobre os Estupefacientes, Nações Unidas, Conselho Económico e Social, Viena.

11. El Sohly MA, Arafat ES, Jones AB. Analysis of the major metabolites of $\triangle 9$-THC in urine. III. A GC/ECD procedure, $J$ Anal Toxicol 1984;8:7-9. 
12. Turner CE, El Sohly MA, Boeren EG. Constituents of cannabis sativa L. XVII. A review of the natural constituents. J Nat Prod. 1980;43:169-234.

13. Huestis MA. Cannabis (Marijuana) - Effects on human behavior and performance. Forensic Sci Rev. 2002; 14: 16-60.

14. Abraham Ann. Media Content Analysis of Marijuana's Health Effects in News Coverage; Journal of General Internal Medicine. September 2018; 33(9):1438-40.

15. India Times; (April 18, 2017); Uttara khand to become first Indian state to legalize cannabis cultivation; https://www.indiatimes.com/news/india/uttarakhand-tobecome-first-indian-state-to-legalise-cannabis-cultivation247769.html

16. Gorea E, Lombard MC: The possible participation of a dopaminergic system in mutilating behavior in rats with forelimb differentiation. Neurosci Lett 1984;48(1):75-80

17. Linszen D, van Amelsvoort T: Cannabis and psychosis: an update on course and biological plausible mechanisms. Curr Opin Psychiatry 2007;20(2):116-20.

18. Goldstein RZ, Volkow ND: Drug addiction and its underlying neurobiological basis: neuro imaging evidence for the involvement of the frontal cortex. Am J Psychiatry 2002; 159(10):1642-52.

How to cite this article: Khan MK,Azmat J, Ahmad F. A case of self slitting of throat as a result of cannabis induced psychosis. Int J Forensic Med Toxicol Sci.2019;4(4):146-8. 